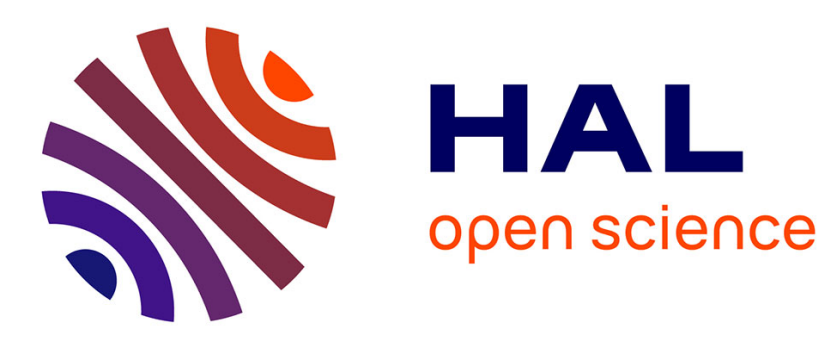

\title{
On the Complex Relationship Between ICT Systems and the Planet
}

\author{
Norberto Patrignani, Iordanis Kavathatzopoulos
}

\section{To cite this version:}

Norberto Patrignani, Iordanis Kavathatzopoulos. On the Complex Relationship Between ICT Systems and the Planet. 13th IFIP International Conference on Human Choice and Computers (HCC13), Sep 2018, Poznan, Poland. pp.181-187, 10.1007/978-3-319-99605-9_13 . hal-02001949

\section{HAL Id: hal-02001949 \\ https://hal.inria.fr/hal-02001949}

Submitted on 31 Jan 2019

HAL is a multi-disciplinary open access archive for the deposit and dissemination of scientific research documents, whether they are published or not. The documents may come from teaching and research institutions in France or abroad, or from public or private research centers.
L'archive ouverte pluridisciplinaire HAL, est destinée au dépôt et à la diffusion de documents scientifiques de niveau recherche, publiés ou non, émanant des établissements d'enseignement et de recherche français ou étrangers, des laboratoires publics ou privés. 


\title{
On the Complex Relationship between ICT Systems and the Planet
}

\author{
Norberto Patrignani ${ }^{1[0000-0001-6422-1994]}$ and Iordanis Kavathatzopoulos ${ }^{2}$ \\ ${ }^{1}$ Politecnico of Torino, Torino, Italy \\ norberto.patrignaniepolito.it \\ ${ }^{2}$ Uppsala University, Uppsala, Sweden \\ iordanis.kavathatzopouloseuu.se
}

\begin{abstract}
This paper addresses the challenges of designing sustainable Information and Communication Technology (ICT) systems. The complexity of ICT systems, the number of stakeholders involved (technology providers, policy makers, users, etc.), and the extension and global scale of ICT supply chain are the main challenges at the core of the complex relationship between ICT systems and the planet Earth. ICT offer an opportunity for an exchange between matter-energy and information: the better use of information offers the great opportunity for decreasing the environmental impact of human activities by decreasing the matter and energy consumption. But, on the other side, like any human activity, the design, production, use, and disposal of complex ICT systems, has as a consequence a growth in entropy. This intriguing dilemma is one of the most difficult challenges in front of designers, ICT companies, users, and policy makers. This paper concentrates on the designers, the engineers' dilemmas: what are the ethical competences, the skills, the methods for addressing these complex ethical dilemmas? Among the many ethical approaches, the "virtue / future ethics" is proposed as a core ethical competence for the designers and engineers of the future.
\end{abstract}

Keywords: Information and Communication Technology (ICT), Entropy, Future Ethics, Fairphone, Slow Tech.

\section{Introduction}

ICT systems are probably the most complex artifacts ever built by humans. Starting at chip level the number of fundamental electronic components (e.g. transistors) can easily reach the number of billions. Then these chips are inserted inside systems containing thousands of components at device level. These devices nowadays are interconnected with other billions of devices, etc. As a result we have a complexity that can easily reach the level of the human brain, the most complex result of natural evolution: 1011 neurons [1]. And this is just a rough estimation based only on the hardware side of ICT, if one includes also the software side, then complexity of the emerging systems exponential. 
Since their first realizations, in the 1950s, computers and ICT systems have been applied in a growing number of fields: from offices, to public authorities, to the general society. Today, many activities that once required a great amount of energy can be executed with the use of ICT systems. This implies a great amount of saving in energy consumption, pollution, and $\mathrm{CO}_{2}$ release: for example a wise use of ICT can save, by 2030, $12.1 \mathrm{GtonCO}_{2}$, (1.8 in power generation, 3.6 in transports and mobility, 2.0 in agriculture, 2.0 in buildings and energy management, 2.7 in manufacturing [2]. On the other side, the power consumed during ICT use and application (all electronic systems are powered with electricity) generates an amount of $\mathrm{CO}_{2}$ of about $1.25 \mathrm{GtonCO}_{2}$ ( 0.59 for powering end users devices, 0.3 for powering voice and data networks, and 0.36 for powering the data centers). As a result, the saving looks interesting: $-10.85 \mathrm{GtonCO}_{2}$.

But there are other dimensions of the scenario: like any human activity, the design, production, use, and disposal of complex ICT systems, has as a lot of consequences in the material consumed in the design/production phase, and in a growing amount of ewaste at their end-of-life; in few words, ICT systems have, as a consequence, a growth in entropy. What is the balance of these opposite effects of ICT? How can designers and engineers face these challenges? What are the ethical competences needed? And how can these ethical competences be acquired?

\section{ICT entropy balance}

\subsection{Material consumption}

Starting from the Personal Computing era, in 1980s, and further accelerating in the 1990s with the Web, the number of people using computers and the network have reached about 4.1 billions of people in 2018 [3]. Also, starting from January 2007, with the launch of the first smart-phone, a device connected to the network with a simple interface based on a touchscreen, about 7.5 billions of these "pocket" computers have been produced and distributed into the society [4]. Producing this number of devices required a huge amount of minerals and materials. For example, the highest "material intensity" in manufacturing is the one related to chips: producing one gram of a memory chip requires 850 grams of materials, fossil fuels, and chemicals; producing one gram of a microprocessor chip requires 3,440 grams of the same resources [5]. In particular it is important to underline that the most indispensable of these materials are the so called "rare-earths"; the seventeen rare-earth elements are Scandium (Sc), Yttrium (Y), plus the fifteen "Lanthanide": Lanthanum (La), Cerium (Ce), Praseodymium (Pr), Neodymium (Nd), Promethium (Pm), Samarium (Sm), Europium $(\mathrm{Eu})$, Gadolinium (Gd), Terbium (Tb), Dysprosium (Dy), Holmium (Ho), Erbium $(\mathrm{Er})$, Thulium $(\mathrm{Tm})$, Ytterbium $(\mathrm{Yb})$, and Lutetium $(\mathrm{Lu})$, they are dispersed throughout the earth's crust and they are difficult to mine. For example the Indium, one of the precious minerals essential for building displays, have been consumed in a total of 71 tons since the beginning of smart-phones era started in 2007; at the current rates of Indium extraction levels there are only 14 years of supply remaining [4]. Even more 
controversial is the origin of many of these minerals coming from war areas in Africa, like the so-called "conflict minerals" [6]. Can ICT be sustainable in the long-term at the current pace of material consumption?

\subsection{Power Consumption}

The dilemma about information-energy is one of the most debated in the history of science. It was James Clerk Maxwell that in 1867 triggered this discussion with the famous "Maxwell's demon" mental experiment where an high speed creature, able to discriminate between fast and slow molecules, as a consequence was creating a difference in temperature against the law of entropy: "... if we conceive of a being whose faculties are so sharpened that he can follow every molecule ... He will thus, without expenditure of work, raise the temperature of $\mathrm{B}$ and lower that of $\mathrm{A}$, in contradiction to the second law of thermodynamics..." (J.C.Maxwell, letter to P.G.Tait, 11 December 1867) [7]. But acquiring information requires an expenditure of energy, as physicist and inventor Leo Szilard demonstrated in 1929, and Leon Brillouin described in 1953: information does not come for free [8,9]. Today it has even been calculated the amount of energy required for computing just 1 bit [10]:

$$
W=K_{b} T \ln 2(\text { Joule })
$$

where: $\mathrm{K}_{\mathrm{b}}=1.38 \times 10^{-23}\left(\mathrm{~J} /{ }^{\circ} \mathrm{K}\right)$, is the Boltzmann's constant, $\mathrm{T}=$ Temperature in ${ }^{\circ} \mathrm{K}=$ $273.15+\mathrm{t}\left({ }^{\circ} \mathrm{C}\right)$, and $\ln 2=0.69315$ (logarithm in base $\mathrm{e}=2.718$ ). For example the minimum amount of energy required for computing 1 bit at the temperature $\mathrm{t}=25^{\circ} \mathrm{C}$ $\left(\mathrm{T}=298.15^{\circ} \mathrm{K}\right)$ is about $285.5 \times 10^{-23} \mathrm{Joule}$, and the corresponding power consumed for computing $1 \mathrm{bit} / \mathrm{sec}$ is $285.5 \times 10^{-23}$ watt, 1 byte/sec is $2,284 \times 10^{-23}$ watt, etc. Nowadays it is well known that the world energy consumption just for datacenters (where it is concentrated the computing power of the planet) has been about $416 \mathrm{TWh}$ (TeraWatt-hours), just for reference, in 2016 the entire country of Italy consumed about $310 \mathrm{TWh}$ of energy [11]. And this is just the $10 \%$ of the entire energy consumption of ICT. Other contributions are: $20 \%$ is due to networks, $45 \%$ to fixed lines access and $25 \%$ to mobile access. But just for smartphones the total energy consumption since their introduction in 2007 is about 968 TWh (73\% for manufacturing, 19\% for use, $6 \%$ distribution, and $2 \%$ for disposal). What will be, in the long term, the source of this growing power needed for running the ICT infrastructure?

\section{3 e-waste}

The problem of e-waste (discarded electronic devices, because at their end-of-life or just for fashion reasons) is one of the most urgent issues for long-term ICT sustainability and its informal processing in developing countries leads to dangerous impact on human health and on the environment (since in all ICT devices are contained many hazardous substances). For example, in 2014, the United Nations University estimated that: roughly 42 million tons of e-waste was generated despite the value and the risk of related materials; smart-phones contributed for 3 million tons to this growing 
mountain of e-waste since it will reach 50 million metric tons in 2017 [12]. The first challenge is to investigate the destination of these devices at the end of their life, since they are sent to destinations where their management is very dangerous. The Blacksmith Institute and Green Cross Switzerland estimated that the most polluted place in the world is Agbogbloshie, close to Accra in Ghana, a mountain of e-waste growing at a rate of 215,000 tons per year [13].

The entire ICT community and in particular the ICT industry and the designers and engineers of ICT systems should immediately start to face this challenge for the longterm ICT sustainability. Priority action is the recycling of ICT devices: for example, the cost of recycling gold from old computers is in the same order of the cost of mining the mineral [14]. However, the crucial step is in the hands of designers and engineers, it is in the choices made at design stage: ICT should be required to be recyclable-by-design (and repairable-by-design). Of course this would be facilitated if the interfaces of all modules are inter-operable and public, like in open software and open hardware [15]. In the long-term a more radical action could be a comprehensive industrial design and development ("regenerative design"), the industrial products should start to be seen as organisms with circulating materials creating waste-free systems [16].

\section{The Ethical Competence of ICT Engineers}

Indeed the challenges outlined in ICT are very difficult, not only because the stakeholders network of ICT is extended at global scale and complex. Or because the design challenges for ICT designers are still looking for practical solutions (e.g. recyclable-by-design, repairable-by-design, etc.). The examples of best-practices are till very rare and very few ICT companies have adopted these innovative and futureproof approaches. One well-known example is the little Dutch company designing the Fairphone [17]. Even the international advocacy organization Greenpeace has recently released a very intriguing report with a ranking among the seventeen world's leading ICT vendors with reference to their environmental impacts by evaluating energy use, resource consumption, and chemical elimination [18]. But there is a growing interest in a more deep question: is it enough to close the cycles? Or it is needed to slow down the ICT consumption cycles? [19]. From another point of view, it is emerging a new competence needed for engineers: an ethical competence. The main ethical approaches are consequentialism (focuses on the consequences of actions), deontology (focuses on actions themselves) and virtue ethics (focuses on the acting person and his/her character traits). Virtue ethics, even if formulated by Aristotle in 350 B.C., it is still relevant for engineers. Indeed facing the ICT long-term sustainability requires many virtues to engineers: expertise/professionalism, clear and informative communication, cooperation, willingness to make compromises, objectivity, being open to criticism, stamina, creativity, striving for quality, having an eye for details, and being in the habit of reporting on work carefully [20]. Also, virtue ethics 
involves also practical wisdom: the ability to make ethical judgments in complex situations, in a real context [21]. All in all, engineers need the skills to handle this multitude and complexity of the above issues, i.e. they need the virtue of phronesis [22]. The virtue of phronesis is the ability to think like a God, i.e. to run the process of thinking in the right way. Accordingly, focus of research and education in ICT ethics should be on thinking, developing the skills to think in the right way [23]. Long-term sustainability concerns the future of the planet and the future generations. One of the first thinkers concentrating on these issues was Hans Jonas: he proposed the need for appropriate technological choices with regard to the planet and future generations [24]. He proposed, probably for the first time in philosophy, to include also future generations in the ethical debate: the pace of ICT development is exactly at the center of this issue due to its exponential growth in power speed. Another ethical approach interesting in this context is the "future ethics". For the first time in our history, we start to imagine that, at the extreme, some consequences of our actions (not just of natural evolution) could bring us into a world without us. Can we imagine this scenario? And how does this future scenario influence our present behavior? And what kind of ethics are we going to use for deciding what is right and what is wrong? What could the norms that will steer us in the right direction be? What can designers and engineers learn from future ethics? A very good example is the so called "climatechange" issue: $\mathrm{CO}_{2}$, as a by-product generated from combustion of fossil-fuels is considered the main component of greenhouse gases that, by increasing their concentration in the atmosphere, has led to an increase in the world's average temperature, the so called green-house effect [25]. As seen above, also ICT is contributing to this green-house effect. What do all these issues have in common? At least two characteristics are present: they are irreversible, and have serious consequences for future generations. So the only wise action is to start reducing the $\mathrm{CO}_{2}$ emissions as soon as possible. A time dimension in our ethical analysis needs then to be addressed. But what are the new characteristics of our scenario when we think about time? For example, what does it mean to act quickly? Does that mean that time is running out? This is crucial for understanding possible future outcomes and for taking action now. The awareness (and knowledge) of the future become the background for taking action into the present. But what actions? In designing ICT systems this is the most critical issue. How can we introduce this time dimension in our ethical analysis? Jonas suggested to introduce "new stakeholders" in our philosophical and ethical debate: the planet and future generations. How are we responsible in front of them? This direction will bring us into a new outcomes-driven ethics (strongly linked with utilitarianism and consequentialism), very different from a rights-driven ethics. Our action is driven by some urgency, by some forecasted results. But how can designers balance the rights of living and future generations? Here starts the conflict between living in the present time and and in the future time. This is the core problem of future ethics. What are the conditions that will convince ICT designers, policymakers (and ICT users) to take actions now, to change behaviors now, to steer technology developments now in a direction that is appropriate for taking into account these future risks? How do we face the actual risk, that people enter now into a kind of fatalism and refuse to think, to discuss, to understand and, finally, to change their behavior now? The 
tsunami of emerging technologies is overwhelming us at such a speed that project leaders, engineers, science and technology researchers (and policy makers) have many difficulties in recognizing social and ethical issues in new fields like ICT. Historically, we apply ethics to us and to relations among us, the human beings living in the present time. The problem with emerging ICT systems is that in many cases the consequences of their deployment are projected into a so distant future that we miss the direct interactions with the consequences of our actions (who care if in 2080 Indium is exhausted?). What if our actions will have an impact, not only on the next generations (our children and grandchildren, with which we will have some kind of interactions), but mostly to long-distant future generations? Until the last century the impact of human activities was mainly concentrated in terms of scope (the cities and their neigh-boroughs) and in terms of time (the present or next generation). Since few years this has changed. Indeed, new developments in some areas of ICT systems have the potentiality of impacting the entire planet and the future of many generations, the scope and time are at another scale, another order of magnitude. A good example of an impact on long-distant future generations is the nuclear waste management problem: even the best initiatives for addressing this issue (like Onkalo, the under construction long-term storage for all nuclear waste produced in Finland) have to accept that the nuclear waste will remain dangerous for more than 100,000 years: hundred millennia is a time that on the human scale is close to eternity, the saecula saeculorum [26]. Here a completely new urgency, not just for philosophers or ethicists, but for all researchers and in general for all of us emerges: how can we develop a new stage of ethics, an ethics that will drive our behavior and inform our decisions when the consequences of our acts are so distant in the future? [27].

\section{Conclusions}

Further studies and actions, for example education focused on supporting thinking in handling ICT ethics issues, are needed for developing the ethical competences for ICT designers and engineers. If these are the ethical competences needed by engineers, how can these ethical competences be acquired? Recently some of the world's most important academic institutions have recognized the need of introducing, as mandatory subject, foundations of ethics in computer science: the next generations of engineers need to be not just experts but also aware of the social and ethical impact of ICT [28]. In particular virtue ethics and future ethics are the most promising approaches for addressing the ethical issues of long-term sustainability of ICT and for understanding the complex relationships between ICT systems and the planet.

\section{$5 \quad$ References}

1. Herculano-Houiel, S.: The Human Brain in Numbers: A Linearly Scaled-up Primate Brain, Frontiers in Human Neuroscience, 3, 31 (2009). http://doi.org/10.3389/neuro.09.031.2009. 
2. GeSI: ICT Solutions for 21 st Century Challenges, Global e-Sustainability Initiative, http://smarter2030.gesi.org/, last accessed 2018/1/20.

3. Internetstats: Internet Usage Statistics, The Internet Big Picture, World Internet Users and 2017 Population Stats, www.internetworldstats.com/stats.htm, last accessed 2018/1/20.

4. Greenpeace: From Smart to Senseless: The Global Impact of 10 Years of Smart-phones (2017).

5. SVTC: Silicon Valley Toxics Coalition, October (2007).

6. Vazquez-Figueroa, A.: Coltan, Ediciones B (2010).

7. Leff, H., Rex, A.F.: Maxwell's Demon, Entropy, Information, Computing, CRC Press (1990).

8. Szilard, L.: On the reduction of entropy in a thermodynamic system by the intervention of intelligent beings, Zeitschrift für Physik. 53 (11-12): 840-856 (1929).

9. Brillouin, L.: Negentropy Principle of Information, Journal of Applied Physics, V24(9) (1953).

10. Landauer R.: Irreversibility and heat generation in the computing process, in IBM Journal of Research and Development, vol. 5, pp. 183-191 (1961).

11. Ericsson: ICT and Power, Energy Performance Report 2016 (2016).

12. Baldé, C.P., Wang, F., Kuehr, R., Huisman, J.: The Global e-waste Monitor, United Nations University (2014).

13. Bernhardt, A., Gysi, N.: (eds) The Worlds Worst 2013: The Top Ten Toxic Threats, Blacksmith Institute, Green Cross Switzerland (2013).

14. Step: Solving the e-waste problem, www.step-initiative.org, last accessed 2018/1/20.

15. Arduino: Arduino: an open source electronics platform, http://www.arduino.cc, last accessed 2018/1/20.

16. Lovins, L.H.: Rethinking production, State of the World 2008 - Innovations for a Sustainable World, The Worldwatch Institute, Washington, D.C. (2008).

17. Fairphone: The modular phone that's built to last, www.fairphone.com, last accessed 2018/1/20.

18. Greenpeace:Guide to Greener 2017, http://www.greenpeace.org/greenerguide.org, last accessed 2018/1/20.

19. Patrignani, N., Whitehouse, D.: Slow Tech and ICT. A Responsible, Sustainable and Ethical Approach, Palgrave-MacMillan, 2018, ISBN 978-3-319-689449 (2018).

20. Pritchard, M.S.: Responsible engineering. The importance of character and imagination, Science and Engineering Ethics, 7 (3), 391-402 (2001).

21. Van de Poel, I., Royakkers, L.: Ethics, Technology, and Engineering. An Introduction, Wyley-Blackwell (2011).

22. Aristotle: Nicomachean Ethics, Papyros, Athens (1975).

23. Arendt, H.: Responsibility and judgement, Schocken, New York (2003).

24. Jonas H.: The Imperative of Responsibility: In Search of an Ethics for the Technological Age, University of Chicago Press, Chicago, IL (1985).

25. Nova: Enhanced greenhouse effect - a hot international topic, Nova, Australian Academy of Science (2008).

26. Madsen, M.: Into Eternity: A Film for the Future. https://www.imdb.com/title/tt1194612/?ref_=nm_ov_bio_lk1, last accessed 2018/1/20.

27. Birnbacher, D.: What motivates us to care for the (distant) future?, Working Papers $\mathrm{N}^{\circ} 04 / 2006$. Iddri, 2006. 27 p., Conference by Dieter Birnbacher, Seminar on Sustainable Development, 21 February 2006 (2006).

28. Singer, N.: Tech's Ethical 'Dark Side': Harvard, Stanford and Others Want to Address It, New York Times, 12 February 2018. 